\title{
Fish target strengths for use in echo integrator surveys
}

\author{
Kenneth G. Foote \\ Institute of Marine Research, 5011 Bergen, Norway
}

(Received 18 July 1986; accepted for publication 25 May 1987)

\begin{abstract}
In situ measurements of fish target strength are selected for use in echo integrator surveys at 38
$\mathrm{kHz}$. The results are expressed through equations in which the mean target strength TS is regressed on the mean fish length $l$ in centimeters. For physoclists, TS $=20 \log l-67.4$, and for clupeoids, TS $=20 \log l-71.9$. These equations are supported by independent measurements on tethered, caged, and freely aggregating fish and by theoretical computations based on the swimbladder form. Causes of data variability are attributed to differences in species, behavior, and, possibly, swimbladder state.
\end{abstract}

PACS numbers: 43.30.Gv, 43.80.Ev, 43.80.Jz, 43.30.Dr

\section{INTRODUCTION}

Fish target strength is a key quantity in the acoustic assessment of fish abundance. ${ }^{1}$ It is essential for expressing echo integrator measurements as quantities of fish. This is evident from the operating principle of the echo integrator: The calibrated output signal from the echo sounder, which is already compensated for geometric spreading and absorption, is squared and integrated over a defined range interval. ${ }^{2}$ The result due to a single ping is proportional to the sum of the backscattering cross sections weighted by the product of transmit and receive beam pattern factors for each scatterer, if sufficiently separated in range. If individual echoes overlap, then the same result applies in the largenumber limit, either of scatterers or observations, because of use of a pulsed sinusoidal signal.

In any case, the echo integrator measures the cumulative backscattering cross section of observed scatterers. If the echoes are due to fish, then the integrator value, after scaling by an integrated beam pattern factor, among others, can be converted to numbers of fish by dividing by the appropriate mean backscattering cross section. It is this quantity, or target strength when expressed logarithmically, that is addressed here.

The history of attempts to determine fish target strength has been reviewed by Midttun. ${ }^{1}$ Ehrenberg has particularly reviewed in situ methods. ${ }^{3}$ By general admission, the measurement is problematical. Fortunately, the coincidence of new or improved instruments and techniques has led to many promising measurements over the past several years.

It is the aim of this article to select those in situ measurements of target strength that, for the time being at least, appear to be most reliable for use by echo sounding and integrating systems operating at $38 \mathrm{kHz}$, the most widely used surveying frequency. The data are compared with collateral measurements and theoretical predictions.

A secondary aim is accomplished by noting the rather large degree of variation in the in situ data. The consequent need to account for the survey situation in applying specific target strengths to echo integrator data is discussed.

\section{IN SITU MEASUREMENTS}

\section{A. Dual-beam system}

The dual-beam system was introduced by Ehrenberg in $1974 .{ }^{4}$ For each transmission, echoes are observed simultaneously on each of two concentric, circular beams. By observing the ratio of echo strengths due to the same target, and knowing the calibration, the angle of the target from the acoustic axis can be determined. This, in turn, allows compensation for the beam pattern loss on either of the beams, hence direct determination of the target strength.

The system, in the improved version described in Ref. 5, has been used to measure the in situ target strengths of walleye pollock (Theragra chalcogramma) ${ }^{5,6}$ and Pacific whiting (Merluccius productus). ${ }^{7}$ The results are shown in Table I.

In the table and everywhere else in this article, the fish length refers to the total length. Thus the use of fork length (FL) in Refs. 5-7 requires conversion to total length (TL). This was done through the following relations specified by R. Baxter of the Northwest and Alaska Fisheries Center, Seattle, WA: $\mathrm{FL}=0.975 \mathrm{TL}$ for walleye pollock and $\mathrm{FL}=0.976 \mathrm{TL}$ for Pacific whiting.

\section{B. Split-beam system}

The present split-beam system was developed by SIMRAD Subsea. It was introduced in $1984 .^{8}$ Division of the transducer into quadrants allows separate processing of each of four signals. These are combined in pairwise fashion. Observation of the phase differences between the port and starboard half-beams and between the fore and aft half-beams allows the target direction to be specified. Again, as with the dual-beam system, this allows compensation for the beam pattern loss in the total signal: the summed port and starboard half-beam signals. Thus the target strength can be directly determined.

Target strengths of the following species have been measured in situ with the split-beam system: cod (Gadus morhua), saithe (Pollachius virens), haddock (Melanogrammus 


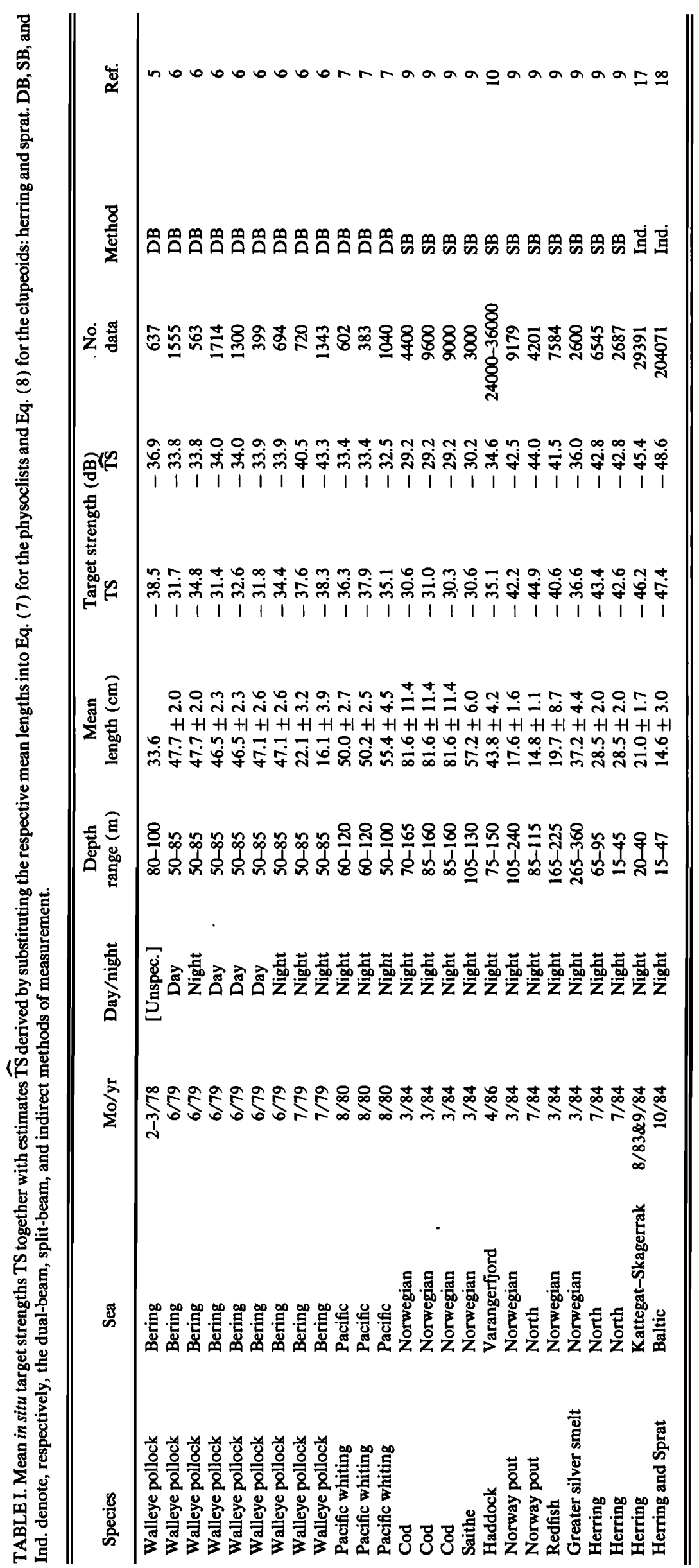


aeglefinus), Norway pout (Trisopterus esmarki), redfish (Sebastes marinus), greater silver smelt (Argentina silus), and herring (Clupea harengus) ${ }^{9,10}$ Details of the measurements are given in Table $I$.

\section{Single-beam system}

Data gathered with a single transducer beam can also be used to determine target strength. Unlike the direct methods, in which each measurement of echo strength can be translated into a target strength value, many measurements of echo strength are required for reduction to target strength. There are a number of ways of accomplishing this reduction, which essentially solves an integral equation. ${ }^{11-16}$

For present purposes, only one method is of interest. It is the linearized solution by Craig and Forbes, ${ }^{11}$ but with addition of the important constraint that the numerical solution be non-negative. ${ }^{17}$ The results of applying this indirect method to single-beam data on herring and sprat (Sprattus sprattus) $)^{17,18}$ are presented in Table I.

\section{DATA ANALYSIS}

The basic acoustic datum in Table $I$ is the mean target strength TS. This is determined from the mean backscattering cross section $\sigma$ according to the following definition ${ }^{19,20}$ :

$$
\text { TS }=10 \log \sigma / 4 \pi \text {. }
$$

Averaging of the individual single-fish measurement results in each of Refs. 5-7, 9, 10, 17, and 18 was performed consistently in the physically correct domain, with units of area. Several estimates of in situ target strength could not be included in the present analysis because the original single-fish data were averaged in the logarithmic domain.

Reduction of the data in Table $I$ is conveniently effected by regressing mean target strength on the logarithm of mean fish length. The analysis is performed in accordance with the usual least-mean-squares criterion for each of two equations,

$$
\mathrm{TS}_{1}=m \log l+b_{1}
$$

and

$$
\mathrm{TS}_{2}=20 \log l+b_{2} \text {, }
$$

where $l$ is the mean fish length in centimeters. The first equation, (2a), resembles earlier two-coefficient equations used by Love, ${ }^{21,22}$ McCartney and Stubbs, ${ }^{20}$ and Nakken and Olsen. ${ }^{23}$

The second equation, (2b), follows a later practice by Love, ${ }^{24}$ due to observation of the approximate proportionality of $\sigma$ and $l^{2}$. This applies to the present, commercially interesting fish species and sizes when observed at $38 \mathrm{kHz}$. An advantage of using the one-coefficient form of the regression equation is that comparisons of different data sets are facilitated. Justification for the use of Eq. (2b) instead of Eq. $(2 a)$ is ultimately established through the statistical significances of the several regressions, given the aim of simplicity.

\section{RESULTS}

Results of analyzing subsets of the data in Table $I$, according to the several regression equations, are shown in Table II. Because of the general scarcity of in situ measurements of target strength, it is desirable to combine as many data as possible in each regression analysis. At the same time, doubts about the quality or representativeness of the data makes unavoidable their discrimination by swimbladder type, time of collection, or even measurement method. This is why the number of analyses in Table II rivals the number of basis data.

A major biological difference among the species of Table I is due to the swimbladder. The clupeoids, herring and sprat, are physostomes, as their swimbladder has a duct communicating with the alimentary canal, hence exterior. These clupeoids lack rete mirabile, moreover, hence, they cannot produce or resorb gas to regulate the swimbladder volume in a controlled manner under depth excursions. The other species of Table I are physoclists, with closed swimbladders. The presence of rete mirabile in these fishes does allow regulation of the swimbladder volume, as, for example, in maintaining neutral buoyancy over the normal depth range of occurrence.

The first measure of discrimination of the acoustic data is, therefore, the swimbladder type. Prior experience also suggests a significant difference in the target strengths of comparably sized physostomes and physoclists. Data from the two types are treated separately in the regression analyses. This is justified by the results shown in the first and last rows of Table II: The mean target strength of a physoclist is

\begin{tabular}{|c|c|c|c|c|c|c|c|c|c|}
\hline \multirow[b]{2}{*}{ Fish } & \multirow[b]{2}{*}{ Day/night } & \multirow[b]{2}{*}{ Method } & \multirow{2}{*}{$\begin{array}{l}\text { Mean-length } \\
\text { range }(\mathrm{cm})\end{array}$} & \multirow{2}{*}{$\begin{array}{l}\text { No. } \\
\text { data }\end{array}$} & \multicolumn{3}{|c|}{$\mathrm{TS}_{1}=m \log l+b_{1}$} & \multicolumn{2}{|c|}{$\mathrm{TS}_{2}=20 \log l+b_{2}$} \\
\hline & & & & & $m$ & $b_{1}$ & SE & $b_{2}$ & SE \\
\hline Physoclists & Both & DB,SB & $14.8-81.6$ & 21 & 15.8 & -60.8 & 2.1 & -67.5 & 2.3 \\
\hline Gadoids & Both & DB,SB & $14.8-81.6$ & 19 & 15.7 & -60.5 & 2.2 & -67.6 & 2.4 \\
\hline Physoclists & Night & DB,SB & $14.8-81.6$ & 16 & 14.9 & -59.8 & 1.9 & -67.9 & 2.4 \\
\hline Gadoids & Night & DB,SB & $14.8-81.6$ & 14 & 14.8 & -59.7 & 2.1 & -68.0 & 2.5 \\
\hline Physoclists & Day & DB & $47.7-48.9$ & 4 & 29.7 & -81.9 & 0.6 & -65.5 & 0.6 \\
\hline Physoclists & Night & DB & $16.5-56.8$ & 7 & 5.1 & -44.5 & 1.3 & -68.1 & 3.7 \\
\hline Physoclists & Night & SB & $14.8-81.6$ & 9 & 18.5 & -65.4 & 1.1 & -67.8 & 1.2 \\
\hline Physoclists & Both & DB & $16.5-56.8$ & 12 & 9.2 & -50.0 & 2.3 & -67.3 & 3.0 \\
\hline Walleye pollock & Both & DB & $16.5-48.9$ & 9 & 13.3 & -55.5 & 1.9 & -66.2 & 2.3 \\
\hline Walleye pollock & Night & DB & $16.5-48.9$ & 4 & 8.2 & -48.4 & 0.3 & -66.0 & 3.5 \\
\hline Clupeoids & Night & Ind.,SB & $14.6-28.5$ & 4 & 15.7 & -66.1 & 0.8 & -71.9 & 1.1 \\
\hline
\end{tabular}

TABLE II. Regression analyses of mean in situ target strength on fish length in centimeters, according to Eqs. (2a) and (2b). SE denotes the standard error. DB, SB, Ind. denote, respectively, the dual-beam, split-beam, and indirect methods. 
roughly $5 \mathrm{~dB}$ higher than that of a comparably sized clupeoid.

Differences in family composition of the physoclists provide another basis for distinguishing the data in their regression analyses. In particular, the fish can be divided into gadoids, or members of the cod family, and nongadoids, redfish and greater silver smelt in the present case. The difference here is insignificant, however, for the target strengths of the two nongadoid physoclists determine the equation TS $=20 \log l-67.3$. This is fully compatible with the respective results in the first and second rows of Table II.

Variation in target strength with time of day, which is probably connected with changes in light intensity, thence orientation distribution, is a recognized phenomenon, ${ }^{6,23,25}$ although quantification of the difference has been difficult. Intercomparison of the data in rows 3-5 of Table II is suggestive of a difference, with the daytime target strength being the greater. Because there are only four daytime data, all of which were gathered with the dual-beam system, these data are also compared with the nighttime data from the same system, in row 6. A difference is again observed, by comparing the results for the second regression equation, but this may be attributed to the influence of the low-valued Pacific whiting data, collected only at night.

Measurements with the split-beam system were only made successfully at night. The result for the second equation in row 7 compares favorably with that in row 6 for the dual-beam system, although the standard error of the dualbeam data is much larger. Further comparison of the splitbeam data with the full set of dual-beam data, including both day and night measurements, in row 8 , shows consistency for the second equations, but not for the first. The slope of the dual-beam data, as determined in the first regression equation, is clearly less than that of the split-beam data in all instances.

A final biological discrimination of the data is made on the species level. Because of the relatively large number of data on walleye pollock, these have been examined separately in rows 9 and 10, to which the analysis in row 5, consisting exclusively of daytime data on walleye pollock, should be added. Use of the second regression equation shows the data to be quite similar, at least within the rather broad limits defined by the standard error.

\section{COMPARISONS}

The difficulty of measuring target strength in situ has long been a spur to controlled-fish measurement. Not least among its advantages is knowing exactly what the target is, for example, species and length. However, the chronic problem with ex situ measurement is its connection with the in situ situation. Almost always, one or more ingredients necessary for making the connection are missing. The applicable orientation and spatial distributions of the fish and the state of the swimbladder are frequent prominent unknowns.

There is hope that the understanding gained through controlled-fish measurement will help resolve some of the ambiguity surrounding in situ measurements. The degree of variation in data, as witnessed specifically by the size of the standard error in Table II, is a case in point. What exactly are the measurements revealing, assuming that they are not concealing faults in equipment operation or analysis technique? Are the target strengths sensitive functions of species, time of day, or behavior? Which of these factors is most important? How much do the individual factors contribute to the variation?

Clearly, these questions cannot be answered here. There are simply too few data for this. However, it is hoped that there are enough data to put some bounds on the degree of variation, hence magnitude of the problem. This is the motivation behind the following detailed comparisons. In every case, these apply to the nominal $38-\mathrm{kHz}$ frequency.

\section{A. Tethered-single-fish measurement}

The precedent for this measurement was established by Midttun and Hoff in $1961{ }^{26}$ The technique was further developed by, among others, Nakken and Olsen in $1971 .{ }^{23}$ It has been used in Bergen since then in this modified form.

In brief, a near-surface-adapted fish is immobilized, for example, by stunning or anesthetization, then tethered to a suspension system allowing its systematic rotation. An upwards-pointing transducer is located directly beneath the fish, at about 10-m range. Repeated ensonification and recording of the fish echo under rotation determines an angle dependence of the target strength. The orientation of the fish, e.g., normal, upside down, or side aspect, is controlled by attaching a small float to the fin or other member. For applications with vertical echo sounders, the most important aspect is the dorsal, and the most important angle is tilt.

In order to apply tethered-single-fish measurements to fish in the wild, the dorsal aspect target strength functions of tilt angle are averaged with respect to a specific mode of behavior. This is generally characterized by the probability distribution of tilt angle. ${ }^{23,27}$ The spatial distribution of the fish is assumed to be homogeneous everywhere in the farfield of the transducer, with half-beamwidth of $5 \mathrm{deg}$, as measured from the acoustic axis. The averages are combined through a regression analysis, as in Eqs. (2a) and (2b).

\section{Lepsøy 1971 data}

These data were gathered by Nakken and Olsen on Lepsøy in $1971 .{ }^{23}$ The gadoid data consist of 171 dorsal aspect target strength functions distributed by species as follows: 68 cod, 59 saithe, and 44 pollack (Pollachius pollachius) ${ }^{28}$ The represented lengths vary from 6.7 to $96.0 \mathrm{~cm}$.

The only in situ measurements of gadoid tilt angle are those by Olsen for spawning cod in Lofoten. ${ }^{29}$ The composite distribution for the day and night data is essentially normal, with a mean of $-4.4 \mathrm{deg}$ and a standard deviation of $16.2 \mathrm{deg}$, i.e., $\mathrm{N}(-4.4,16.2)$. Averaging of the 171 functions with respect to this distribution and performance of the regression analyses in Eqs. (2a) and (2b) determine the following equations:

$$
\mathrm{TS}_{1}=21.3 \log l-68.3
$$

and

$$
\mathrm{TS}_{2}=20 \log l-66.3,
$$


TABLE III. Regression analyses of tethered-single-fish target strength measurements, described in Sec. III A, for tilt angle distributions observed in situ.

\begin{tabular}{|c|c|c|c|c|c|c|c|c|c|c|c|}
\hline \multirow[b]{2}{*}{ Fish } & \multirow[b]{2}{*}{ Year } & \multicolumn{3}{|c|}{ Tilt angle distribution } & \multirow{2}{*}{$\begin{array}{l}\text { Length } \\
\text { range }(\mathrm{cm})\end{array}$} & \multirow{2}{*}{$\begin{array}{l}\text { No. } \\
\text { data }\end{array}$} & \multicolumn{3}{|c|}{$\mathrm{TS}_{1}=m \log l+b_{1}$} & \multicolumn{2}{|c|}{$\mathbf{T S}_{2}=20 \log l+b_{2}$} \\
\hline & & $\bar{\theta}$ & $\mathbf{s}_{\theta}$ & $\mathrm{D} / \mathrm{N}$ & & & $m$ & $b_{1}$ & SE & $b_{2}$ & SE \\
\hline $\begin{array}{l}\text { Gadoids } \\
\text { Pollack }\end{array}$ & $\begin{array}{l}1971 \\
1980\end{array}$ & $\begin{array}{l}-4.4 \\
-4.4\end{array}$ & $\begin{array}{l}16.2 \\
16.2\end{array}$ & $\begin{array}{l}\text { Both } \\
\text { Both }\end{array}$ & $\begin{array}{r}6.7-96.0 \\
26.0-44.0\end{array}$ & $\begin{array}{r}171 \\
86\end{array}$ & $\begin{array}{l}21.3 \\
16.8\end{array}$ & $\begin{array}{l}-68.3 \\
-62.5\end{array}$ & $\begin{array}{l}1.5 \\
0.9\end{array}$ & $\begin{array}{l}-66.3 \\
-67.3\end{array}$ & $\begin{array}{l}1.5 \\
1.0\end{array}$ \\
\hline $\begin{array}{l}\text { Herring } \\
\text { Sprat } \\
\text { Clupeoids } \\
\text { Herring }\end{array}$ & $\begin{array}{l}1971 \\
1971 \\
1971 \\
1980\end{array}$ & $\begin{array}{l}-3.4 \\
-3.4 \\
-3.4 \\
-3.4\end{array}$ & $\begin{array}{l}10.3 \\
10.3 \\
10.3 \\
10.3\end{array}$ & $\begin{array}{l}\text { Day } \\
\text { Day } \\
\text { Day } \\
\text { Day }\end{array}$ & $\begin{array}{r}10.0-32.4 \\
6.6-17.6 \\
6.6-32.4 \\
16.0-31.0\end{array}$ & $\begin{array}{l}25 \\
21 \\
46 \\
60\end{array}$ & $\begin{array}{r}8.9 \\
12.6 \\
9.8 \\
19.3\end{array}$ & $\begin{array}{l}-55.2 \\
-59.3 \\
-56.4 \\
-68.0\end{array}$ & $\begin{array}{l}1.7 \\
1.6 \\
1.6 \\
1.2\end{array}$ & $\begin{array}{l}-69.5 \\
-67.2 \\
-68.5 \\
-69.1\end{array}$ & $\begin{array}{l}2.5 \\
1.9 \\
2.5 \\
1.2\end{array}$ \\
\hline $\begin{array}{l}\text { Herring } \\
\text { Sprat } \\
\text { Clupeoids } \\
\text { Herring }\end{array}$ & $\begin{array}{l}1971 \\
1971 \\
1971 \\
1980\end{array}$ & $\begin{array}{l}12.0 \\
12.0 \\
12.0 \\
12.0\end{array}$ & $\begin{array}{l}23.5 \\
23.5 \\
23.5 \\
23.5\end{array}$ & $\begin{array}{l}\text { Night } \\
\text { Night } \\
\text { Night } \\
\text { Night }\end{array}$ & $\begin{array}{r}10.0-32.4 \\
6.6-17.6 \\
6.6-32.4 \\
16.0-31.0\end{array}$ & $\begin{array}{l}25 \\
21 \\
46 \\
60\end{array}$ & $\begin{array}{l}11.2 \\
12.0 \\
11.2 \\
21.2\end{array}$ & $\begin{array}{l}-61.3 \\
-62.0 \\
-61.2 \\
-74.2\end{array}$ & $\begin{array}{l}1.8 \\
1.3 \\
1.6 \\
1.1\end{array}$ & $\begin{array}{l}-72.6 \\
-70.6 \\
-71.7 \\
-72.5\end{array}$ & $\begin{array}{l}2.3 \\
1.7 \\
2.3 \\
1.1\end{array}$ \\
\hline
\end{tabular}

which apply with the same standard error of $1.5 \mathrm{~dB}$. These results are also stated in Table III. Use of the particular day and night tilt angle distributions, $\mathrm{N}(-3.6,15.3)$ and $\mathrm{N}(-5.6,17.4)$, respectively, has only a negligible effect.

The clupeoid data consist of the dorsal aspect target strength functions of 25 herring and 21 sprat. The corresponding length ranges are $10.0-32.4 \mathrm{~cm}$ and $6.6-17.6 \mathrm{~cm}$. The functions have been averaged for each of two tilt angle distributions, which represent the only in situ observations. These were determined for mature herring by Buerkle. ${ }^{25}$ They are $\mathrm{N}(-3.4,10.3)$ for the daytime and $\mathrm{N}(12.0,23.5)$ for the nighttime. Results are shown in Table III.

\section{Skogsvaag 1980 data}

These data were determined in a similar manner to those of the Lepsøy study. ${ }^{30}$ For this article, the target strength functions of 86 pollack and 60 herring have been used. The represented length ranges are $26.0-44.0 \mathrm{~cm}$ and $16.0-31.0$ $\mathrm{cm}$, respectively. The results of averaging these data in like manner to the Leps $\phi y$ data are shown in Table III.

\section{B. Caged-fish measurement}

A long series of measurements of encaged fish has been performed by the Marine Laboratory in Aberdeen, Scotland. The results for herring held at $17.5-\mathrm{m}$ depth are that the mean target strength of a 24-cm herring is $-42.3 \mathrm{~dB}$ and that of a $9-\mathrm{cm}$ herring is $-50.6 \mathrm{~dB} .{ }^{31}$ These two data determine the relation TS $=19.5 \log l-69.2$ or, similarly,

$$
\text { TS }=20 \log l-69.8 \text {. }
$$

\section{Freely-aggregating-fish measurements}

\section{Preseining echo integration}

In a novel sea experiment in 1982, Hagstr $\phi m$ and $R \phi t-$ tingen conducted a small-scale echo integrator survey on a naturally occurring aggregation of herring extending over the approximate depth range $30-90 \mathrm{~m} .{ }^{32}$ This was, more or less, caught afterwards by a single cast of a purse seiner. Since the acoustic instruments were calibrated and the apparent number of surveyed herring could be counted, the mean target strength per fish could be inferred. It was $-42.7 \mathrm{~dB}$ for herring of mean length $34.6 \mathrm{~cm}$. When used to determine the intercept $b_{2}$ in Eq. (2b), the result is

$$
\text { TS }=20 \log l-73.5 \text {. }
$$

The confidence of this result is unknown because of ignorance over the effectiveness of the seining operation. It is speculated that the number of caught fish is probably accurate to within about $33 \%$, which implies error bounds of $\pm 1.5 \mathrm{~dB}$.

Hagstr $\phi m$ and R $\phi$ ttingen repeated their experiment in 1983 , observing a mean target strength of $-43.3 \mathrm{~dB}$ for herring of mean length $32.3 \mathrm{~cm}$. The determined equation is thus identical with Eq. (5).

\section{Simultaneous echo integration and counting}

Some of the haddock registrations reported by Ona and Hansen ${ }^{10}$ were sufficiently dispersed to permit simultaneous echo integration and counting. Because the echo integrator was calibrated, the area density of fish could be expressed as the quotient of the scaled integrator value and mean backscattering cross section. The area fish density could also be estimated by visually counting the number of individual echo traces on the echogram and relating this number to the mean observed area in the depth layer where the echo traces were counted. ${ }^{33}$ Thus, equating the two expressions for the area density, the mean backscattering cross section could be expressed in terms of measurable quantities. Analysis of echograms, by Ona and Hansen, of dispersed haddock of mean length $43.8 \mathrm{~cm}$ in the depth range $50-150 \mathrm{~m}$ in Varangerfjord on 26 April 1986 yielded 4503 echo traces. The resultant mean target strength was $-34.9 \mathrm{~dB}$. A confidence interval of $\pm 2 \mathrm{~dB}$ was assigned, mainly because of uncertainty in the estimate of mean observed area.

\section{Theoretical computation}

Target strength functions of tilt angle have also been computed on the basis of the swimbladder form. ${ }^{34}$ For the case of 13 pollack and 2 saithe, with lengths from 31.5 to 44.5 $\mathrm{cm}$, the result of averaging the computed functions with re- 
spect to the tilt angle distribution $\mathrm{N}(-4.4,16.0)$ and regressing the averages according to Eq. (2b) is

$$
\text { TS }=20 \log l-66.9 \text {. }
$$

This applies with the standard error $1.7 \mathrm{~dB}$. The identical result is obtained by repeating the averaging and regression procedure for the measured target strength functions of the same 15 specimens, although with standard error of $0.4 \mathrm{~dB}$.

\section{DISCUSSION}

The number of determinations of mean in situ target strength is relatively small. However, many of these have been made on the basis of quite large numbers of measurements, lending credence to them. It is in this context that the regression analyses presented in Table II are to be judged.

\section{A. Internal consistency}

What is perhaps striking about the regression analyses are their similarities and the degree of variability they disclose in the in situ data. The similarities are seen distinctly through the intercept of the second regression equation. For the nonclupeoid data, similar trends are observed without apparent regard to the measurement method. This may, however, be due to the countervailing influences of the target strengths of walleye pollock and Pacific whiting, the first being generally higher and the second lower than corresponding split-beam data.

Discrimination of the data by day and night is not especially illuminating, but then there are only four daytime data. Taken together, these are not much different from the corresponding nighttime data for walleye pollock, although intercomparison of the in situ data for walleye pollock of the same length suggests that the daytime values exceed the nighttime ones by about $3 \mathrm{~dB}$. This has already been noted by Traynor and Williamson, ${ }^{6}$ who argue for assigning the difference to the orientation distribution, which is most likely related to the background light intensity. Buerkle's observations ${ }^{25}$ of the in situ orientation of herring are entirely supportive of this supposition, as are the caged-fish measurements of Edwards and Armstrong. ${ }^{31}$

Ignoring the differences for the time being, the mean in situ target strength of a physoclist of length $l$ can be approximated by the equation

$$
\text { TS }=20 \log l-67.5 \text {. }
$$

This was determined from the 21 physoclist in situ data in Table I with a standard error of $2.3 \mathrm{~dB}$.

There are only four in situ data on the clupeoid target strength. These are fairly consistent, determining regression equations with standard errors of the order of $1 \mathrm{~dB}$; for example,

$$
\text { TS }=20 \log l-71.9 .
$$

Comparison with the physoclist data shows that the clupeoid target strength is about $4.5 \mathrm{~dB}$ less.

\section{B. External consistency}

Comparison of the present empirical findings for physoclists and clupeoids with the corresponding, so-called ex situ data is a most interesting exercise.

Using tethered-single-fish measurements of target strength together with the only in situ observational data on the tilt angle distribution of gadoids, the physoclist equation, (7), is confirmed as follows. For data gathered on $171 \mathrm{cod}$, saithe, and pollack by Nakken and Olsen on Leps $\phi y$ in 1971, the determined equation is TS $=20 \log l-66.3$. For data gathered on 86 pollack by this author at Skogsvaag in 1980, the result is TS $=20 \log l-67.3$.

Simultaneous echo integration and counting on a dispersed aggregation of haddock have produced a datum which determines the equation TS $=20 \log l-67.7$. Further agreement has been obtained through analysis of single-fish target strength functions computed from the gadoid swimbladder form. Both these and the results of analysis of corresponding measured target strength functions determine the same equation, namely TS $=20 \log l-66.9$.

The clupeoid equation, (8), is similarly confirmed. For the data gathered on 46 herring and sprat in 1971, TS $=20 \log l-71.7$, while, for data from 60 herring measured in 1980, TS $=20 \log l-72.5$.

The consistency of measurements on tethered single fish and free-swimming fish should, perhaps, not be surprising in view of the results of the linearity experiment in $1980 .{ }^{30}$ Among other things, this showed that it is possible to compute the echo energy from an aggregation of free-swimming fish on the basis of tethered-single-fish measurements of target strength and knowledge of the orientation distribution of the aggregating fish. This connection has already been exploited in compensating the split-beam measurements for the effects of thresholding and saturation. ${ }^{9}$ Strictly speaking, therefore, some of the split-beam in situ data are not independent of the tethered-fish measurements. However, as shown in Ref. 9, application of Weimer and Ehrenberg's independent, parametric approach to compensation ${ }^{35}$ gives very similar results. Thus the present in situ data may be regarded as being independent of the tethered-fish measurements.

Caged-fish measurements of herring have indicated the equation TS $=20 \log l-69.8$. Measurements made on free aggregations of herring, caught subsequently to the acoustic measurements, have given the result TS $=20 \log l-73.5$.

What is very telling about the ex situ data is their diversity and general independence, distinguished by time, place, species, size distribution, depth, manner of collection, and researchers. Convergence of the respective physoclist and clupeoid data to Eqs. (7) and (8) is unambiguous.

\section{Data variability}

The major problem disclosed by the regression analyses is the degree of variability of the in situ data. As measured by the standard error of the regression, this is often in excess of two decibels. Such a figure is simply too large for use in echo integrator surveys of fish abundance, at least for ordinary management purposes.

Given the overall similarities of physoclist data as measured with the dual-beam and split-beam systems, and agreement of both physoclist and clupeoid in situ data with the 
corresponding ex situ data, the possible causes of the variability are to be sought in the fish biology. Species and behavior are the primary characteristics to be considered.

Both effects are observed to a limited degree in the herring and sprat data in Table III. Similar effects are observed in the gadoid data when differentiated by species. Thus, despite the magnitudes of the standard error, systematic effects based on species and behavior seem sufficient to account for the variability in the mean in situ target strengths.

An additional effect is that of the state of swimbladder inflation. Physoclists with rete mirabile may regulate their swimbladder volume with changing depth. This is not to say that they do or that they always change depth slowly enough to maintain neutral or other condition of buoyancy. The particular clupeoids lack rete mirabile, and can only control their swimbladder volume by releasing gas, which they apparently often do when rising to the surface. The present data are, however, too few to permit convincing analysis.

\section{CONCLUSIONS}

Equations (7) and (8) summarize the in situ measurements on physoclists and clupeoids. These are firmly supported by a wealth of collateral evidence, including echointegrator measurements on tethered, caged, and freely aggregating fish, and theoretical computations based on the swimbladder form.

The standard error associated with the physoclist regression in Eq. (7) is $2.3 \mathrm{~dB}$. This is most likely due to differences in species and behavior. The state of depth adaptation by the swimbladder may also be a contributing factor. Irrespective of the cause of variability, the most suitable target strengths for application in echo integrator surveys are those that reflect the situation, specifically, the biological and physical states of the fish, including behavior, and the external conditions of observation.

In situ measurements of the clupeoid target strength are fewer, but apparently more consistent. The result in Eq. (8) is lower than the standard recommended for use in surveys of herring and sprat coordinated by the International Council for the Exploration of the Sea by $0.7 \mathrm{~dB}$.

'L. Midttun, "Fish and other organisms as acoustic targets," Rapp. P.-v. Réun. Cons. Int. Explor. Mer 184, 25-33 (1984).

${ }^{2}$ K. A. Johannesson and R. B. Mitson, "Fisheries acoustics. A practical manual for aquatic biomass estimation," FAO Fish. Tech. Pap. (240), 1249 (1983).

${ }^{3}$ J. E. Ehrenberg, "A review of in situ target strength estimation techniques," FAO Fish. Rep. (300), 85-90 (1983).

${ }^{4} J$. E. Ehrenberg, "Two applications for a dual-beam transducer in hydroacoustic fish assessment systems," Proc. IEEE Conf. Eng. Ocean Environ. 1, 152-155 (1974).

5J. J. Traynor and J. E. Ehrenberg, "Evaluation of the dual beam acoustic fish target strength measurement method," J. Fish. Res. Board Can. 36, 1065-1071 (1979).

${ }^{6} \mathrm{~J}$. J. Traynor and N. J. Williamson, "Target strength measurements of walleye pollock (Theragra chalcogramma) and a simulation study of the dual beam method," FAO Fish. Rep. (300), 112-124 (1983).

${ }^{7}$ N. J. Williamson and J. J. Traynor, "In situ target strength estimation of Pacific whiting (Merluccius productus) using a dual-beam transducer," J.
Cons. Int. Explor. Mer 41, 285-292 (1984).

${ }^{8}$ K. G. Foote, F. H. Kristensen, and H. Solli, "Trial of a new, split-beam echo sounder," Coun. Meet. Int. Coun. Explor. Sea 1984/B:21, Copenhagen, Denmark.

${ }^{9} \mathrm{~K}$. G. Foote, A. Aglen, and O. Nakken, "Measurement of fish target strength with a split-beam echo sounder," J. Acoust. Soc. Am. 80, 612-621 (1986).

${ }^{10} \mathrm{E}$. Ona and K. Hansen, "In situ target strength observations on haddock," Coun. Meet. Int. Coun. Explor. Sea 1986/B:39, Copenhagen, Denmark.

"R. E. Craig and S. T. Forbes, "Design of a sonar for fish counting," Fiskeri. Skr. Ser. Havunders. 15, 210-219 (1969).

${ }^{12} \mathrm{~J}$. E. Ehrenberg, "A method for extracting the fish target strength distribution from acoustic echoes," Proc. IEEE Conf. Eng. Ocean Environ. 1, 61-64 (1972).

${ }^{13}$ M. L. Peterson, C. S. Clay, and S. B. Brandt, "Acoustic estimates of fish density and scattering function," J. Acoust. Soc. Am. 60, 618-622 (1976).

${ }^{14} \mathrm{~J}$. E. Ehrenberg, T. J. Carlson, J. J. Traynor, and N. J. Williamson, "Indirect measurement of the mean acoustic backscattering cross section of fish," J. Acoust. Soc. Am. 69, 955-962 (1981).

${ }^{15}$ B. J. Robinson, "An in situ technique to determine fish target strength with results for blue whiting (Micromesistius poutassou Risso)," J. Cons. Int. Explor. Mer 40, 153-160 (1982).

${ }^{16}$ C. S. Clay, "Deconvolution of the fish scattering PDF from the echo PDF for a single transducer sonar," J. Acoust. Soc. Am. 73, 1989-1994 (1983).

${ }^{17}$ P. Degnbol, H. Lassen, and K.-J. Staehr, "In situ determination of target strength of herring and sprat at 38 and $120 \mathrm{kHz}$," Dana 5, 45-54 (1985).

${ }^{18} \mathrm{H}$. Lassen and K.-J. Staehr, "Target strength of Baltic herring and sprat measured in situ," Coun. Meet. Int. Coun. Explor. Sea 1985/B:41, Copenhagen, Denmark.

${ }^{19}$ R. H. Love, "Measurements of fish target strength: a review," Fish. Bull. U. S. 69, 703-715 (1971).

${ }^{20}$ B. S. McCartney and A. R. Stubbs, "Measurements of the acoustic target strengths of fish in dorsal aspect, including swimbladder resonance," J. Sound Vib. 15, 397-420 (1971).

${ }^{21}$ R. H. Love, "Maximum side-aspect target strength of an individual fish," J. Acoust. Soc. Am. 46, 746-752 (1969).

${ }^{22} \mathbf{R}$. H. Love, "Dorsal-aspect target strength of an individual fish," J. Acoust. Soc. Am. 49, 816-823 (1971).

${ }^{23} \mathrm{O}$. Nakken and K. Olsen, "Target strength measurements of fish," Rapp. P.-v. Réun. Cons. Int. Explor. Mer 170, 52-69 (1977).

${ }^{24}$ R. H. Love, "Target strength of an individual fish at any aspect," $J$. Acoust. Soc. Am. 62, 1397-1403 (1977).

${ }^{25} \mathrm{U}$. Buerkle, "First look at herring distributions with a bottom referencing underwater towed instrumentation vehicle 'BRUTIV,' " FAO Fish. Rep. (300), 125-130 (1983).

${ }^{26} \mathrm{~L}$. Midttun and $\mathrm{I}$. Hoff, "Measurements of the reflection of sound by fish," Fiskeridir. Skr. Ser. Havunders. 13(3), 1-18 (1962).

${ }^{27} \mathrm{~K}$. G. Foote, "Effects of fish behavior on echo energy: The need for measurements of orientation distributions," J. Cons. Int. Explor. Mer 39, 193-201 (1980).

${ }^{28} \mathrm{~K}$. G. Foote and O. Nakken, "Dorsal aspect target strength functions of six fishes at two ultrasonic frequencies," Fisken og Havet, Ser. B 1978(3), $1-95$.

${ }^{29} \mathrm{~K}$. Olsen, "Orientation measurements of cod in Lofoten obtained from underwater photographs and their relation to target strength," Coun. Meet. Int. Coun. Explor. Sea 1971/B:17, Copenhagen, Denmark.

${ }^{30} \mathrm{~K}$. G. Foote, "Linearity of fisheries acoustics, with addition theorems," J. Acoust. Soc. Am. 73, 1932-1940 (1983).

${ }^{31} \mathrm{~J}$. I. Edwards and F. Armstrong, "Measurement of the target strength of live herring and mackerel," FAO Fish. Rep. (300), 69-77 (1983).

${ }^{32} \mathrm{O}$. Hagstr $\phi \mathrm{m}$ and I. R $\phi t$ tingen, "Measurements of the density coefficient and average target strength of herring using purse seine," Coun. Meet. Int. Coun. Explor. Sea 1982/B:33, Copenhagen, Denmark.

${ }^{33} \mathrm{~L}$. Midttun and $\mathrm{O}$. Nakken, "On acoustic identification, sizing and abundance estimation of fish," Fiskeridir. Skr. Ser. Havunders. 16, 36-48 (1971).

${ }^{34} \mathrm{~K}$. G. Foote, "Rather-high-frequency sound scattering by swimbladdered fish," J. Acoust. Soc. Am. 78, 688-700 (1985).

${ }^{35}$ R. T. Weimer and J. E. Ehrenberg, "Analysis of threshold-induced bias inherent in acoustic scattering cross-section estimates of individual fish," J. Fish. Res. Board Can. 32, 2547-2551 (1975). 